Izvorni znanstveni članak

Original scientific paper

\title{
ANALIZA PORIJEKLA BANIJSKE ŠARE SVINJE
}

\author{
D. Škorput, V. Klišanić, S. Menčik, Ž. Mahnet, D. Karolyi, \\ Z. Luković, K. Salajpal
}

\begin{abstract}
Sažetak
Genetska raznolikost unutar autohtonih pasmina svinja se smanjuje kao posljedica smanjenja veličina populacija. Stoga se posljednjih godina posebna pozornost pridaje očuvanju genetske raznolikosti takvih pasmina. Cilj istraživanja bio je utvrditi genetsku raznolikost banijske šare svinje koristeći podatke o porijeklu životinja. Podaci o porijeklu sadržavali su 721 zapis o porijeklu svinja banijske šare pasmine u razdoblju od 2010 do 2017. godine. Referentna populacija sadržavala je sve životinje iz porijekla. Kvaliteta i cjelovitost pedigrea utvrđena je korištenjem slijedećih parametara: prosječni maksimalni broj generacija praćenih unatrag, prosječan broj punih generacija, te prosječan broj ekvivalentnih generacija. Genetska raznolikost populacije opisana je slijedećim parametrima: prosječni koeficijent uzgoja u srodstvu $(\mathrm{F})$, stopa promjene koeficijenta uzgoja u srodstvu $(\Delta \mathrm{F})$, efektivna veličina populacije $\left(\mathrm{N}_{\mathrm{e}}\right)$, prosječna srodnost u populaciji, te efektivni broj začetnika $\left(\mathrm{N}_{\mathrm{ef}}\right)$. Genetski intervali za četiri selekcijska puta izraženi su kao prosječna dob roditelja u trenutku rođenja potomaka. Prosječni maksimalni broj generacija iznosio je 2,47 , prosječan broj punih generacija 1,50 , dok je prosječni broj ekvivalentnih generacija iznosio 2,00. Prosječni koeficijent uzgoja u srodstvu iznosio je 3,68\%, a stopa promjene uzgoja u srodstvu $1,74 \%$ po generaciji. Prosječna srodnost u populaciji iznosila je 9,32\%, dok je efektivna veličina populacije iznosila 28,81. Prosječno trajanje generacijskog intervala iznosilo je 2,17 godine. Rezultati analize porijekla pokazali su potrebu za ulaganjem dodatnih napora kako bi se očuvala genetska raznolikost unutar populacije banijske šare svinje. Tome može pridonijeti plansko sparivanje životinja te primjena selekcije s optimiziranim doprinosom.
\end{abstract}

Ključne riječi: banijska šara svinja, porijeklo, genetska raznolikost

\section{Uvod}

Banijska šara svinja autohtona je pasmina svinja nastala krajem 19. stoljeća na području Banovine križanjem domaće bijele svinje u tipu landrasa s berkširom i turopoljskom svinjom. Kao kod većine autohtonih pasmina svinja, uvođenjem plemenitih pasmina u uzgoj, smanjila se veličina populacije banijske šare svinje, te je u drugoj polovici 20. stoljeća pasmina postala ugrožena (Salajpal i sur, 2017.). Pokretanjem projekta revitalizacije uzgoja banijske šare svinje, javila se potreba za analizom genetske raznolikosti populacije s ciljem postavljanja programa konzervacije pasmine.

Analiza genetske raznolikosti zasniva se na informacijama o porijeklu životinja, koristeći pokazatelje kao što su koeficijent uzgoja u srodstvu ili koeficijent srodstva između životinja unutar populacije (Caballer i Torro, 2000.). Gubitak genetske raznolikosti svojstven je populacijama koje su prošle kroz smanjenje veličine populacije i posljedično kroz proces ,uskog grla“ (eng. „bottleneck“). Pri tome su smanjenju genetske raznolikosti izloženije male populacije autohtonih pasmina svinja (Fernandes i sur., 2010.), ali i populacije plemenitih pasmina svinja

Doc. dr. sc. Dubravko Škorput, Prof.dr.sc. Danijel Karolyi, izv. Prof.dr.sc. Zoran Luković, Prof. dr. sc. Krešimir Salajpal, Sveučilište u Zagrebu, Agronomski i fakultet, Svetošimunska cesta 25, Zagreb,

Vedran Klišanić, Hrvatska poljoprivredna agencija, Križevačka poljana 185, 48260 Križevci; Sven Menčik, Sveučilište u Zagrebu Veterinarski fakultet, Heinzelova 55, Zagreb 
pod visokim selekcijskim pritiskom (Welsh i sur., 2010.; Melka i Schenkel, 2010.). U takvim populacijama povećan je rizik pojave genetskog drifta i gubitka pojedinih alela iz populacije. Gubitkom genetske raznolikosti također se smanjuje mogućnost budućeg genetskog napretka u populaciji. Stoga se u uzgojnim programima manjih populacija posebna pozornost posvećuje postizanju održive stope promjene uzgoja u srodstvu te primijeni selekcije s optimiziranim doprinosom (Ferndandes i sur., 2001.).

$\mathrm{S}$ obzirom na navedeno, cilj rada je bio analizirati genetsku raznolikost unutar populacije banijske šare svinje korištenjem zapisa porijekla životinja iz baze.

\section{Materijal i metode}

Za analizu genetske raznolikosti unutar populacije banijske šare svinje korišteni su podaci iz baze podataka Hrvatske poljoprivredne agencije. Podaci o porijeklu sadržavali su informacije o precima za 721 životinju u razdoblju od 2010. do 2017. godine. Referentna populacija obuhvaćala je sve životinje s informacijama o porijeklu. Struktura porijekla analizirana je primjenom CFC programskog paketa (Sargolzaei i sur., 2006.). Kvaliteta i cjelovitost porijekla utvrđena je korištenjem slijedećih parametara: prosječni maksimalni broj generacija praćenih unatrag (broj generacija između potomka i najdaljeg poznatog pretka), prosječan broj punih generacija (broj generacija između potomka i najdalje generacije u kojoj poznati broj predaka $2^{\mathrm{g}}$, gdje je g broj generacija), te prosječan broj ekvivalentnih generacija (zbroj $(1 / 2)^{\mathrm{n}}$, gdje je $\mathrm{n}$ broj generacija koja razdvaja životinju od svakog poznatog pretka). Prosječni koeficijent srodstva (F) (Gutiérrez i sur., 2005.) za svaku jedinku definiran je kao vjerojatnost da slučajno odabrani alel iz populacije pripada toj životinji. Efektivna veličina populacije $\left(\mathrm{N}_{\mathrm{e}}\right)$, definirana je kao broj jedinki potreban za ostvarenje trenutne razine uzgoja u srodstvu:

$\mathrm{N}_{\mathrm{e}}=1 /(2 \Delta \mathrm{F})$ (Falconer and Mackay, 1996.),

gdje je $\Delta \mathrm{F}$ stopa promjene koeficijenta uzgoja u srodstvu po generaciji izračunata koristeći ENDOG programski paket (Gutiérrez i Goyache, 2005.). Također, struktura populacije opisana je efektivnim brojem začetnika $\left(\mathrm{N}_{\mathrm{ef}}\right)$. Generacijski intervali definirani kao prosječna dob roditelja u vrijeme rođenja potomaka izračunati su za četiri selekcijska puta: otac-sin, otac-kćer, majka-sin, te majka-kćer.

\section{Rezultati i rasprava}

Broj začetnika bio je 100, što čini 14\% životinja u porijeklu. U Tablici 1. prikazani su rezultati analize kvalitete i cjelovitosti porijekla u referentnoj populaciji banijske šare svinje. Vođenje matičnih knjiga za populaciju banijske šare svinje započeto je 2015. godine, te je zbog kratkog vremenskog razdoblja bilježenja podataka za ovu populaciju porijeklo još uvijek plitko te su parametri koji opisuju kvalitetu i cjelovitost porijekla niski, što se posebno odnosi na prosječni broj punih generacija.

Tablica 1. Kvaliteta i cjelovitost porijekla u referentnoj populaciji banijske šare svinje Table 1 Quality and integrity of pedigree in reference population of Banija spotted pig

\begin{tabular}{ll}
\hline Prosječni maksimalni broj generacija praćenih unatrag & 2,47 \\
\hline Prosječan broj punih generacija & 1,50 \\
\hline Prosječni broj ekvivalentnih generacija & 2,00 \\
\hline
\end{tabular}


Nedovoljna cjelovitost porijekla direktno utječe na točnost procjene parametara genetske raznolikosti. Stoga je točnom bilježenju podataka o porijeklu životinja potrebno dati posebnu pozornost, jer se s povećanjem dubine porijekla povećava točnost procjene parametara populacije i olakšava planiranje procesa konzervacije ugroženih pasmina.

Tablica 2. prikazuje osnovne rezultate analize porijekla banijske šare svinje. Ukupno 208 životinja u porijeklu bilo je uzgojeno u srodstvu. Prosječni koeficijent uzgoja u srodstvu bio je visok te je iznosio je 3,68\%. Ovu vrijednost potrebno je dodatno sagledati u kontekstu niske cjelovitosti porijekla. U slučajevima kada je porijeklo nije cjelovito, koeficijent uzgoja u srodstvu može biti podcijenjen, kao u slučaju krškopoljske pasmine svinja (Malovrh i sur., 2012.). Slične vrijednosti koeficijenta uzgoja u srodstvu uočene su u populaciji crne slavonske svinje (Lukić i sur., 2015.) i bijele $(3,86 \%)$ i lasaste mangulice $(3,29 \%)$ te više $(5,02 \%)$ u populaciji crvene mangulice (Posta i sur., 2016.). Koeficijent uzgoja u srodstvu u populaciji je relativno visok i odraz je sparivanja srodnih životinja u prethodnim generacijama. Međutim, u svrhu konzervacije pasmine i smanjenje rasta uzgoja u srodstvu u budućim generacijama te posljedično očuvanja genetske raznolikosti, informativnije mjere su stopa promjene koeficijenta uzgoja u srodstvu $(\Delta \mathrm{F})$ te efektivna veličina populacije $\left(\mathrm{N}_{\mathrm{e}}\right)$. Stopa promjene koeficijenta uzgoja u srodstvu iznosila je $1,74 \%$ a efektivna veličina populacije 28,81 . Prema preporukama Organizacije za poljoprivredu i hranu Ujedinjenih naroda (FAO, 2000.), stopa uzgoja u srodstvu ne bi trebala prelaziti $1 \%$, a efektivna veličina populacije ne bi trebala biti manja od 50. Stoga, populacija banijske šare svinje spada u skupinu pasmina niske genetske raznolikosti, što je specifična odlika većine autohtoih pasmina svinja.

Tablica 2. Rezultati analize porijekla banijske šare svinje

Table 2 Results of pedigree analysis of Banija spotted pig

\begin{tabular}{ll}
\hline Prosječni koeficijent uzgoja u srodstvu $(\mathrm{F})$ & $3,68 \%$ \\
\hline Prosječna srodnost & $9,32 \%$ \\
\hline Stopa uzgoja u srodstvu $-\Delta \mathrm{F}$ & $1,74 \%$ \\
\hline Efektivna veličina populacije - $\mathrm{N}_{\mathrm{e}}$ & 28,81 \\
\hline Broj začetnika/Efektivni broj začetnika - $\mathrm{N}_{\mathrm{ef}}$ & $98 / 17$ \\
\hline
\end{tabular}

Tako se, ovisno o liniji, efektivna veličina populacije iberijske svinje procijenjena na temelju porijekla kretala između 16,0 i 57,7 (Silió i sur., 2015.). Također, prema rezultatima istraživanja Crovettija i sur. (2013.), niska efektivna veličina populacije zabilježena je i u talijanskih autohtonih pasmina Cinta Senese $(40,32)$ i Mora Romagnola $(10,87)$.

Nisku genetsku raznolikost potvrđuju i ostali parametri koji opisuju genetsku raznolikost populacije. Tako je prosječna srodnost u populaciji 9,32\%, a efektivni broj začetnika 9. Višestruko manji efektivni broj začetnika u odnosu na broj začetnika također upućuje na nisku genetsku raznolikost unutar populacije. Prosječna srodnost u populaciji krškopoljske pasmine svinja iznosila je 5\% (Malovrh i sur., 2012.), pri čemu autori navode da je vrijednost vjerojatno podcijenjena zbog necjelovitog porijekla. Slične vrijednosti uočene su u populacijama bijele i lasaste mangulice, dok je visoka srodnost usporediva s rezultatima ovog istraživanja uočena u populaciji crvene mangulice (Posta i sur., 2016.). Usporedbom s istraživanjima na talijanskim 
autohtonim pasminama, uočene su slične vrijednosti za efektivni broj začetnika kao u pasmine Cinta Senese $\left(\mathrm{N}_{\mathrm{ef}}=11\right)$, te veće vrijednosti nego u pasmine Mora Romagnola $\left(\mathrm{N}_{\mathrm{ef}}=2\right)($ Crovetti i sur., 2013.). Također, autori navode da se rezultati se zasnivaju na plitkom porijeklu, te se može očekivati da će s većom količinom informacija u porijeklu doći do realnije procijene prosječnog uzgoja u srodstvu.

Tablica 3. Genetski intervali u populaciji banijske šare svinje Table 3 Generation intervals in Banija spotted pig population

\begin{tabular}{lcc}
\hline \multicolumn{1}{c}{ Selekcijski put } & Prosječni generacijski interval & Standardna devijacija \\
\hline Otac-sin & 1,91 & 0,75 \\
\hline Otac-kćer & 2,07 & 1,06 \\
\hline Majka-sin & 2,02 & 0,88 \\
\hline Majka kćer & 2,56 & 1,44 \\
\hline Ukupno & 2,17 & 0,03 \\
\hline
\end{tabular}

Najkraći genetski interval uočen je kod selekcijskog puta otac-sin, dok je najdulji genetski interval zabilježen kod selekcijskog puta majka-kćer (Tablica 3.). Krupa i sur. (2015.) utvrdili su najkraći generacijski interval kod selekcijskog puta otac-sin, a najduži kod selekcijskog puta majka-kćer u pet plemenitih pasmina svinja, što je u skladu s rezultatima dobivenima u ovom istraživanju. Međutim, prosječno trajanje generacijskog intervala kraće je u plemenitih pasmina, što je posljedica bržeg ulaska u rasplodnu uporabu svinja plemenitih pasmina te razlike između načina upravljanja reprodukcijom u stadima autohtonih, češće ekstenzivno držanih pasmina svinja i plemenitih, uglavnom intenzivno držanih pasmina svinja. Trajanje generacijskih intervala dobivenih u ovom istraživanju usporedivi su s istraživanjem Poste i sur. (2016), koji su analizirali trajanje generacijskih intervala u tri soja mangulice. Međutim, najkraći generacijski interval zabilježen je kod selekcijskog puta majka kćer, dok je kod dva soja mangulice najduži genetski interval uočen kod selekcijskog puta otac-sin.

\section{Zaključci}

Rezultati analize genetske raznolikosti banijske šare svinje na temelju informacija o porijeklu životinja pokazali su potrebu za ulaganjem dodatnih napora kako bi se očuvala genetska raznolikost unutar populacije banijske šare svinje. Jedna od mjera je ujednačavanje doprinosa pojedinih životinja unutar populacije. Stoga je potrebno planirati sheme sparivanja životinja kako bi se postigla održiva stopa rasta uzgoja u srodstvu. S povećanjem broja životinja i genetske raznolikosti populacije, moguća je i primjena selekcije s optimiziranim doprinosom, $\mathrm{s}$ ciljem istovremenog postizanja genetskog napretka u populaciji za određena svojstva i održanja genetske raznolikosti populacije banijske šare svinje. 


\section{LITERATURA}

1. Caballero, A., , M.A. Toro (2000.): Interrelations between effective population size and other pedigree tools for the management of conserved populations, Genetical Research, 75, 331-343.

2. Crovetti, A., F. Sirtori, C. Pugliese, O. Franci, R. Bozzi (2013.): Pedigree analysis of Cinta Senese and Mora Romagnola breeds breeds. Acta Agriculturae Slovenica, Suppl. 4, pp. 41-44.

3. Falconer, D.S., T.F.C. Mackay (1996.): Introduction to Quantitative Genetics. Longman, Essex, U.K., $4^{\text {th }}$ edition.

4. FAO (2000.): Secondary guidelines for development of national farm animal genetic resources management plans: Management of small populations at risk. UN Food and Agric. Org.

5. Fernandez, J., M.A. Toro, M. Caballero (2001.): Practical implementation of optimal management strategies in conservation programmes: a mate selection method. Animal Biodiversity and Conservation 24 (2): 17-24.

6. Fernándes, S.D., S. Malovrh, M. Kovac, V. Cadavez. (2010.): Study of genetic diversity of Bisaro pigs breed by pedigree analysis, Lucrări Ştiințifice. SeriaZootehnie. 53(15): 326-330.

7. Gutiérrez, J.P., F. Goyache (2005.): A note on ENDOG: a computer program for analysing pedigree information, Journal of Animal. Breeding and Genetics, 122, 357-360.

8. Krupa, E., E. Žáková, Z. Krupová (2015.): Evaluation of inbreeding and genetic variability of five pig breeds in Czech Republic, Asian-Australian Journal of Animal Science, 28(1):25-36.

9. Lukić, B., A. Smetko, Ž. Mahnet, V. Klišanić, M. Špehar, Raguž, N., Kušec, G. (2015.): Population genetic structure of autochthonous Black Slavonian Pig, Poljoprivreda, S1 28-32.

10. Malovrh, Š., M. Planinc, M. Kovač (2012.): Genetic structure of Krškopolje pig based on pedigree data, Options Méditerranéennes : Série A. Séminaires Méditerranéens; 101:75-79.

11. Melka, M.G., F. Schenkel (2010.): Analysis of genetic diversity in four Canadian swine breeds using pedigree dana, Canadian Journal of Animal Science, 90(3): 331-340.

12. Posta, J., P. Szabó, P. Komlósi (2016.): Pedigree analysis of Mangalitza pigg breeds, Annals of animal science, 16(3):701-709.

13. Salajpal, K., S. Menčik, D. Šalamon, D. Karolyi, V. Klišanić, Ž. Mahnet, D. Škorput, Z. Luković (2017.): Revitalizacija uzgoja banijske šare svinje, Sveučilište u Zagrebu Agronomski fakultet.

14. Sargolzaei, M. H. Iwaisaki, J.J. Colleau (2006.): CFC: A tool for monitoring genetic diversity. $8^{\text {th }}$ World Congress on Genetics Applied to Livestock Production. Belo Horizonte, Brazil,August 13-18 2006, MinasCentro Convetion Centre.

15. Silió, L., C. Barragán, A.I. Fernández , J. García-Casco, M.C. Rodríguez (2015.): Assessing effective population size, coancestry and inbreeding effects on litter size using the pedigree and SNP data in closed lines of the Iberian pig breed, Animal Breeding and Genetics, 133 (2):145-154.

16. Welsh, C.S., T.S. Stewart, C. Schwab, H.D. Blackburn (2010): Pedigree analysis of 5 swine breeds in the United States and the implications for genetic conservation, Journal of Animal Science, 85 (5): 16101618. 


\section{PEDIGREE ANALYSIS OF BANIJA SPOTTED PIG}

\section{Summary}

Genetic diversity of local and autochthonous populations of pigs is contracting due to reduced population sizes of such populations. In recent decades special attention is given to the preservation of genetic diversity of local and autochthonous populations of pigs. The aim of this study was to estimate the genetic diversity and breed structure of BS pig breed using pedigree data. Complete pedigree file contained 721 animals of Banija spotted pig. The reference population contained all pigs born between 2010 and 2017. Quality and integrity of the pedigree information were evaluated by the following parameters: by the average number of maximum generations traced back, the average number of full generations, and the average number of complete equivalent generations. Genetic diversity of the population was described by the following parameters: average inbreeding coefficient $(F)$, inbreeding rate $(\Delta F)$, effective population size $\left(\mathrm{N}_{\mathrm{e}}\right)$, average relatedness, and effective number of founders $\left(\mathrm{N}_{\mathrm{ef}}\right)$. Generation intervals for four selection paths were expressed as average age of parents when the offspring were born. The average maximum number of generations was 2.47 , average number of full generations was 1.50 , while average number complete equivalent generations was 2.00 . The inbreeding coefficient obtained by pedigree analysis was $3.68 \%$. The inbreeding rate per generation was $1.74 \%$ and effective population size was 28.81. Average generation interval was 2.17 years. Results of the genetic diversity analysis by the pedigree data showed that further efforts in conservation of Banija spotted pig breed should be focused on the creating mating schemes with a goal to control of the rate of inbreeding and further loss of genetic diversity.

Keywords: Banija spotted pig, pedigree, genetic diversity

Primljeno: 04.10.2018.

Prihvaćeno: 18.12.2018. 